Brit. J. prev. soc. Med. (1976), 30, 71-78

\title{
Disability: a model and measurement technique
}

\author{
R. G. A. WILliAMS, M. JOHNSTON, L. A. WILlIS, AND A. E. BENNETT \\ Health Services Evaluation Group, Department of the Regius Professor of Medicine, University of Oxford, Oxford
}

\begin{abstract}
Williams, R. G. A., Johnston, M., Willis, L. A., and Bennett, A. E. (1976). British Journal of Preventive and Social Medicine, 30, 71-78. Disability: a model and measurement technique. Current methods of ranking or scoring disability tend to be arbitrary. A new method is put forward on the hypothesis that disability progresses in regular, cumulative patterns. A model of disability is defined and tested with the use of Guttman scale analysis. Its validity is indicated on data from a survey in the community and from postsurgical patients, and some factors involved in scale variation are identified. The model provides a simple measurement technique and has implications for the assessment of individual disadvantage, for the prediction of progress in recovery or deterioration, and for evaluation of the outcome of treatment regimes.
\end{abstract}

In the assessment of disability two problems have emerged-What items of activity are relevant? What could validate the scoring or grading assigned?

In choosing items of activity for assessment an intuitive consensus has evolved. This assumes that the most important activities are those that are frequently and uniformly required by custom-the so-called activities of daily living. However, other criteria have been applied and some have taken as important those disabilities which require assistance from other people; but whether as a value judgement, or as an interpretation of customary values, this is challengeable. Recently Sainsbury (1973) has argued that the limitation of choice suffered by the disabled should be taken into account. Ekwall (1966) and Wood (1974) take the widest possible range of handicaps that are associated with impairment.

Apart from this problem of item choice, the validity of gradings cannot be taken for granted. Recently a national survey of the disabled in Great Britain (Harris, 1971) made broad judgements of personal handicap in an eight-grade assessment of disadvantage. An earlier international survey used a simple scoring system to mark the degree of a person's incapacity (Shanas et al., 1968) and it is interesting to compare these two assessments. First, there is considerable difference in the activities covered. The national survey based its grading on capacity for self-care: the international survey included items of mobility. However, even where the items are similar, there are interesting differences in judgements. Take, for example, two cases:

Case 1 = puts on her own shoes with difficulty cannot wash all over

Case 2 = cannot put on her shoes or stockings cannot do up her buttons cannot dress without help in some other respects

These are ranked in a reverse order of seriousness by the two surveys as follows:

\begin{tabular}{|c|c|c|}
\hline & $\begin{array}{c}\text { National SURVEY } \\
\text { (Harris, 1971) }\end{array}$ & $\begin{array}{c}\text { INTERNATIONAL } \\
\text { SURVEY } \\
\text { (Shanas } \text { et al., 1968) }\end{array}$ \\
\hline Case 1 & $\begin{array}{c}\text { Seventh worst } \\
\text { handicap }\end{array}$ & $\begin{array}{c}\text { (Shanas } \\
\text { Third worst } \\
\text { incapacity }\end{array}$ \\
\hline Case 2 & $\begin{array}{l}\text { Fifth worst } \\
\text { handicap }\end{array}$ & $\begin{array}{l}\text { Fourth worst } \\
\text { incapacity }\end{array}$ \\
\hline
\end{tabular}

Discrepancies of this kind do not matter much in building up a broad picture of the disabled population by survey methods. But where assessment of an individual's need is the criterion for benefits, the arbitrary ranking or scoring methods which are currently in use will clearly not have the necessary degree of sensitivity. Moreover, when there has to be an arbitrary judgement, it will be desirable at least to identify the cases affected by it, so that they may receive special consideration. 
Validating a Disability Scale: A New Model

In this paper we have not attempted a formal solution to the problem of item choice, as the data presented were collected for other purposes; whenever the data offered a choice of items we have merely indicated briefly the considerations guiding our selection. The validation of a scoring system is thus our main topic.

Current validation of the scoring or ranking assigned to disabilities may be termed empirical. Wylie and White (1964) tested their scoring against subsequent death, or improvement as assessed by a physician. Other tests have included the demand for nonfamily help after discharge (Katz et al., 1963) and time spent by nurses to move the patient (Schoening et al., 1965). More recently there has been an ingenious use of court awards to indicate the value attached to different ranks of disability (Rosser and Watts, 1972). By contrast Harris (1971) was unsuccessful in an attempt to obtain ratings of disability by the disabled. The variety of these attempts may reflect a lack of uniformity in the empirical implications of disability.

In creating and validating a scale of items we have preferred to aim at 'construct validity,' an approach which requires that the scale should behave in accordance with an intuitive construct or concept of disability. There is a widespread appreciation of some progressive pattern in disability, and it has been suggested that this pattern is essentially cumulative. A cumulative pattern is observable in many kinds of growth or decay. New abilities are added to old in childhood; new handicaps are added to old in a degenerative illness. This intuition was first explored in the rehabilitation of disabled patients by Katz et al. (1963), whose hypothesis was that the relearning of very basic abilities such as continence, feeding, and washing followed the same pattern taken by learning in infancy. About the same time Carroll (1962) explored similar orderings in the recovery of patients who had suffered a stroke. Harris and Luck (1972) explored cumulative orderings within specific areas of more general activity-household maintenance, self care, and mobility-using survey data which will be re-examined in part of this paper. However they did not integrate these orderings, preferring for their purposes to align them into a descriptive classification with three parallel gradings and no strict implication of hierarchy.

Our work was developed upon these hints, which suggested that disability would fit the cumulative model developed by the mathematician Louis Guttman after the second world war, and known as Guttman scaling (Guttman, 1950).
The attraction of the Guttman scale model, if it is found to be appropriate for the data, is in the quite? simple solution it provides to the problem of scaling disability. In assigning individuals to a cumulative? scale of disadvantage, one can avoid intuitive comparisons between different disabilities. Insteaces. when a severer disability occurs, it will be in con? junction with the lighter disabilities, so that the order of disadvantage can be made out simply by counting the number of disabilities. In data of the Guttman scale pattern, seven disabilities are always worse than six so long as two assumptions hold good-each disability is regarded as a disadvantage and the activity items scored are representative. solution is also provided for the identification of errors. Individuals whose disabilities do not follow the scale pattern are immediately apparent. discussion of the method will make this clear.

The cumulative characteristic of the scale can be illustrated by taking three activities which have an obvious cumulative order of recovery for a sick person:

\section{Getting up}

2. Going out of the house

3. Going back to work.

The relationship between these three items caథ be translated into the basic tenet of the Guttman scale: that if we know how many of the items wer\& counted as disabled, we can name which items If two items were counted as disabled, we can name them as (2) going out of the house and (3) going back to work. In choosing from these three items we should rarely be wrong, but the occasions whe we are wrong count as errors, or as indicating the existence of a nonscale type. If a score of 1 counts as disabled and 0 as able on any item, scale. types and nonscale types for three items wid appear as follows:

$\begin{array}{cc}\text { Scale TyPes } & \text { Nonscale TyPes } \\ 111 & 101 \\ 011 & 110 \\ 001 & 100 \\ 000 & 010\end{array}$

If a group consists entirely of scale types, w can say that the cumulative scale concerned unidimensional for that group. However, a perfeet scale is improbable: measurement error, samplif error, and random variation among individuas militate against perfection. Accordingly, the procedure sets up a hypothesis postulating the existene of a Guttman scale structure in a given body of data, and tests this hypothesis against the propos tion of errors. 
The conventional levels for acceptable error are based on mathematical and statistical explorations of the technique, but they do not have an interpretation in sampling error terms. Hence it is possible, in searching for Guttman scales, to capitalize on chance alignments of the data. The conventions are, therefore, relatively stringent, but even so, a Guttman scale should ideally be further confirmed by replication.

The conventional levels are measured by two coefficients. The coefficient of reproducibility gives the proportion of all item disabilities correctly predicted from a knowledge of the number of each respondent's disabilities. Item reproducibilities give the equivalent proportion of each item's disabled scores so predicted. Conventionally an overall reproducibility of 0.9 confirms the existence of a valid cumulative and unidimensional Guttman scale. Further tests are also recommended, one of which is the coefficient of scalability (Menzel, 1953). This may be important for the following reasons. The coefficient of reproducibility partly reflects variation in the proportion of people disabled under each item. This is quite proper as the proportion scoring positively on an item usually increases progressively when a cumulative scale exists. But the variation could also occur by chance, and reproducibility could be high because of the variation alone. In naming the items on which somebody scores by predicting from the number of disabilities he scores in total, we could sometimes do quite well simply by naming the items which were most frequently scored disabled. In fact the reproducibility of a scale cannot be less than the sum of the majority responses to each item divided by the total number of responses. The coefficient of scalability tells us what proportion of the remaining responses could be correctly predicted using the scale hypothesis, and values of 0.6 or higher have been suggested as indicating a valid Guttman scale. Procedures for testing Guttman scaling are more fully explained elsewhere (Torgerson, 1958).

\section{EXAMPLE I}

Guttman Scaling of Disability In the Community Data obtained during 1967 in a household survey of the disabled in Lambeth were studied for Guttman scale structures. The survey method and results of this survey have been reported previously (Bennett, Garrad, and Halil, 1970; Garrad and Bennett, 1971). Altogether 88 men and 157 women aged between 35 and 74 years were identified as being disabled in one or more of four areas of activity: self-care, domestic duties, mobility, and occupation.

Items for scaling were chosen so as to be applicable to most people. Items on occupation and use of stairs were excluded for the total group as many people were retired or lived in single-floor accommodation. Women were not scaled on travelling alone, as this was not habitual for many quite able women of the older generation. Men were not scaled on household duties for the same reason. However, the scalings of people at work and of men who kept house were considered separately. Of the four areas of activity described in the Lambeth data, occupation was included only for a special group, and items in the other three areas were included as follows:

1. Self-care. In feeding, using the w.c., dressing, undressing, and washing, those who were helped by another person were counted disabled.

2. Domestic duties. Respondents identified their own shopping, cooking, cleaning, and washing requirements, and if they said they did none or only part of an item, they were counted as disabled with one exception: the extended family was often strong in Lambeth, and domestic duties might be shared between women of different households who were quite fit; thus those who preferred sharing were not regarded as disabled.

3. Mobility. Personal choice of activities was best indicated by mobility. Four item definitions were chosen for scaling which corresponded as far as possible to access to all parts of a room, access to all rooms, access to the neighbourhood, and access beyond the neighbourhood. It was assumed that a wider choice of activities was available to those who had a wider area open to them.

\section{Results}

The scaling obtained for women is shown in Table I. Overall reproducibility and scalability are well above the conventional level for indicating a valid Guttman scale. The scaling obtained for men is shown in Table II. Similar reproducibility and scalability are apparent. Compared with the women's scale, there is an interchange between the washing and dressing items, and between the use of the w.c. and the sitting/standing items. However, the switches are between items on a very similar level of occurrence, and may be due to chance. 
TABLE I

DISABILITY IN THE COMMUNITY: LAMBETH WOMEN

\begin{tabular}{|c|c|c|}
\hline $\begin{array}{l}\text { Grade }= \\
\text { No. Items } \\
\text { Disabled }\end{array}$ & $\begin{array}{l}\text { Item Disability } \\
\text { Added at Each Grade }\end{array}$ & $\begin{array}{c}\text { Item } \\
\text { Repro- } \\
\text { ducibility }\end{array}$ \\
\hline 1 & $\begin{array}{l}\text { Cannot do all own washing } \\
\text { clothes, cleaning, shopping }\end{array}$ & 0.96 \\
\hline 2 & $\begin{array}{l}\text { Does not use transport } \\
\text { accompanied }\end{array}$ & 0.82 \\
\hline 3 & $\begin{array}{l}\text { walk out of doors } \\
\text { unaccompanied }\end{array}$ & 0.90 \\
\hline 4 & Cannot do all own cooking $\ldots$ & 0.90 \\
\hline 5 & wash without help $\quad$. & 0.97 \\
\hline 6 & dress without help $\ldots$ & 0.94 \\
\hline 7 & undress without help .. & 0.94 \\
\hline 8 & $\begin{array}{l}\text { use w.c. or commode } \\
\text { without help }\end{array}$ & $1 \cdot 00$ \\
\hline 9 & $\begin{array}{l}\text { sit and stand without } \\
\text { help }\end{array}$ & $1 \cdot 00$ \\
\hline 10 & Does not get out of bed & $1 \cdot 00$ \\
\hline \multirow[t]{2}{*}{11} & $\underset{\text { Cannot eat without personal }}{\text { help }}$ & $1 \cdot 00$ \\
\hline & $\begin{array}{l}\text { Coefficient of reproducibility ... } \\
\text { Coefficient of scalability }\end{array}$ & $\begin{array}{l}0.95 \\
0.69\end{array}$ \\
\hline
\end{tabular}

TABLE II

DISABILITY IN THE COMMUNITY: LAMBETH MEN

\begin{tabular}{|c|c|c|}
\hline $\begin{array}{l}\text { Grade = } \\
\text { No. Items } \\
\text { Disabled }\end{array}$ & $\begin{array}{l}\text { Item Disabliity } \\
\text { Added at Each Grade }\end{array}$ & $\begin{array}{c}\text { Item } \\
\text { Repro- } \\
\text { ducibility }\end{array}$ \\
\hline 1 & $\begin{array}{l}\text { Cannot use bus or train } \\
\text { unaccompanied }\end{array}$ & 0.93 \\
\hline 2 & $\begin{array}{l}\text { Does not use transport } \\
\text { accompanied }\end{array}$ & 0.93 \\
\hline 3 & $\begin{array}{l}\text { walk out of doors } \\
\text { unaccompanied }\end{array}$ & 0.93 \\
\hline 4 & Cannot dress without help $\ldots$ & 0.88 \\
\hline 5 & wash without help $\quad$. & 0.92 \\
\hline 6 & undress without help .. & 0.92 \\
\hline 7 & $\begin{array}{l}\text { sit and stand without } \\
\text { help }\end{array}$ & 0.98 \\
\hline 8 & $\begin{array}{l}\text { use w.c. or commode } \\
\text { without help }\end{array}$ & 0.99 \\
\hline 9 & Does not get out of bed & 0.99 \\
\hline \multirow[t]{2}{*}{10} & Cannot eat without personal help & 0.99 \\
\hline & $\begin{array}{l}\text { Coefficient of reproducibility } \ldots \\
\text { Coefficient of scalability }\end{array}$ & $\begin{array}{l}0.95 \\
0.71\end{array}$ \\
\hline
\end{tabular}

Special Groups

After the exclusion of men and women who did not need to work (owing to a private income or, for women, after marriage) or who had retired at the recognized age, separate scales including an occupational item were examined. Respondents? were counted as being disabled if they had obtained $\overline{\bar{c}}$. altered hours or job requirements, or shelteredo employment, through a medical recommendation, $\bar{O}$ or if they had suffered premature retirement or $\overline{\bar{s}}$ unwilling loss of work. No important differences $\mathbb{\Phi}$ from the general scales were observed, and the occupation item could simply be added to the top end of the scale. Thus the first item to be modified. through impairment for this group was work.

The 18 men who kept house, however, showed a difference in ordering from women (Table III). $\frac{.}{\circ}$ Like women, they limited aspects of their housework? first, but they were slower to relinquish independent $\omega_{0}^{\omega}$ mobility, preferring to accept help with cookingiv before they would do so.

Women, in general, would limit their mobility rather 0 than accept unwanted help with their cooking. But $\triangle$ interestingly, there was a subgroup of women who $\subseteq$ approximated to the men. Items $2-4$ on the women's scale (Table I) were seen to carry lower repro- $\overrightarrow{0}$ ducibilities than the rest. In these items the error pattern was not random.

Of the nonscale types, the two which followed the men's ordering were in the majority. Thes nature of the impairment was not apparently related to this pattern. The key to this nonscale group may have been economic position (Table IV). $\stackrel{\mathbb{Q}}{\varrho}$ Social class, or, in the large skilled manual group, $\vec{\overrightarrow{ }}$ the absence of a husband to help, were arguably 3 economic indicators. Women in these stringent $\supset$ circumstances could, however, turn to the extended family network, and close relatives were more $\frac{}{\Phi}$ frequent as 'key helpers' for these women than for $\stackrel{\rho}{\sigma}$ the more fortunate group. For this reason they might have been readier to accept loss of autonomy in the kitchen, since it was more likely to be shared

TABLE III

DISABILITY IN LAMBETH MEN WHO KEEP HOUSE

\begin{tabular}{|c|c|c|}
\hline $\begin{array}{l}\text { Grade = } \\
\text { No. Items } \\
\text { Disabled }\end{array}$ & $\begin{array}{l}\text { Item Disability } \\
\text { Added at Each Grade }\end{array}$ & $\begin{array}{c}\text { Item } \\
\text { Repro- } \\
\text { ducibilities }\end{array}$ \\
\hline 1 & $\begin{array}{l}\text { Cannot do all own washing } \\
\text { clothes, cleaning, shopping }\end{array}$ & $1 \cdot 00$ \\
\hline 2 & all own cooking $\quad$. & $1 \cdot 00$ \\
\hline 3 & $\begin{array}{l}\text { Does not use transport } \\
\text { accompanied }\end{array}$ & 1.00 \\
\hline \multirow[t]{2}{*}{4} & $\begin{array}{l}\text { walk out of doors } \\
\text { unaccompanied }\end{array}$ & $1 \cdot 00$ \\
\hline & $\begin{array}{l}\text { Coefficient of reproducibility .. } \\
\text { Coefficient of scalability }\end{array}$ & $\begin{array}{l}1 \cdot 00 \\
1 \cdot 00\end{array}$ \\
\hline
\end{tabular}


by a daughter or sister, and these relatives, in many neighbouring households, shared household tasks by preference.

If the women are divided into groups of economically insecure (social class III key helper not husband, and social classes IV and V) and economically secure (all the remainder) and the insecure group is scaled like the men who kept house, the following results are obtained:

\section{ECONOMICALLY ECONOMICALLY SECURE INSECURE}

Reproduci-

$\begin{array}{lll}\text { bility } & 0.94 & 0.95 \\ \text { calability } & 0.70 & 0.71\end{array}$

This refinement provides an interesting insight into family functioning and with more precise extended family predictors it may be possible to improve both scales in the future.

The remaining special groups which are of some interest are contained within item 1 of the women's scale. Principally there is a striking difference in the order of limitation for shopping and household cleaning. Women who accept limitation in their household cleaning while postponing limitation in their shopping tend to be suffering from internal ailments, usually in the heart or chest, or to have locomotor impairments in the upper limbs, sometimes including the trunk (Table V). Sensory, mental, lower limb, and mixed impairment lead to earlier impairment of shopping, locomotor impairments being dominant in this group.

This might tend to be interpreted as a straightforward physical limitation on mobility frustrating a normal preference to maintain activity out of doors; however there is an equally striking relationship between household situation and disability ordering (Table VI). The 12 married women, and the three nonmarried women in larger households, usually had a man available to help, and the most conventionally appropriate help he could have offered would be shopping. The nature of the impairment is not necessary to this explanation. However, as would be expected from these tables, impairment and household situation are linked (Table VII). There is some tendency for nonmarried women to have upper limb or internal impairments. Presumably this tendency is antecedent to their current

TABLE IV

LAMBETH WOMEN: SPECIAL SCALE GROUPS RELATED TO ECONOMIC POSITION

\begin{tabular}{|c|c|c|c|c|}
\hline \multicolumn{2}{|c|}{$\begin{array}{l}\text { Husband's } \\
\text { Social } \\
\text { Class }\end{array}$} & $\begin{array}{c}\text { Scale Type: } \\
\text { Cooking Maintained } \\
\text { Walking Limited }\end{array}$ & $\begin{array}{c}\text { Nonscale Type: } \\
\text { Walking Maintained } \\
\text { Cooking Limited }\end{array}$ & $\begin{array}{l}\text { Total } \\
\text { No. }\end{array}$ \\
\hline \multirow{4}{*}{$\begin{array}{l}\text { II, III, } \\
\text { III }\end{array}$} & Non-manual & 6 & 0 & 6 \\
\hline & Manual & & & \\
\hline & $\begin{array}{l}\text { Husband } \\
\text { key helper }\end{array}$ & 4 & 2 & 6 \\
\hline & $\begin{array}{l}\text { Other } \\
\text { key helper }\end{array}$ & 1 & 6 & 7 \\
\hline IV, V & & 2 & 6 & 8 \\
\hline Total no & & 13 & 14 & 27 \\
\hline
\end{tabular}

$P<0.01$ (Likelihood ratio test)

TABLE V

LAMBETH WOMEN: SPECIAL SCALE GROUPS RELATED TO IMPAIRMENT

\begin{tabular}{l|c|c|c}
\hline Impairment & $\begin{array}{c}\text { Shopping Maintained } \\
\text { Cleaning Limited }\end{array}$ & $\begin{array}{c}\text { Cleaning Maintained } \\
\text { Shopping Limited }\end{array}$ & $\begin{array}{c}\text { Total } \\
\text { No. }\end{array}$ \\
\hline $\begin{array}{l}\text { Upper limbs } \\
\text { or internal } \\
\text { Other (lower } \\
\text { limbs, sensory, } \\
\text { mental, etc.) }\end{array}$ & 9 & 3 & 12 \\
\hline Total no. & 6 & 20 & 33 \\
\hline
\end{tabular}


TABLE VI

LAMBETH WOMEN: SPECIAL SCALE GROUPS RELATED TO HOUSEHOLD SITUATION

\begin{tabular}{|c|c|c|c|}
\hline Household & $\begin{array}{l}\text { Shopping Maintained } \\
\text { Cleaning Limited }\end{array}$ & $\begin{array}{l}\text { Cleaning Maintained } \\
\text { Shopping Limited }\end{array}$ & $\begin{array}{l}\text { Total } \\
\text { No. }\end{array}$ \\
\hline $\begin{array}{l}\text { Married or living } \\
\text { with } 3+\text { others }\end{array}$ & 3 & 15 & 18 \\
\hline $\begin{array}{l}\text { Nonmarried, } \\
\text { living alone, or } \\
\text { with one other }\end{array}$ & 12 & 5 & 17 \\
\hline Total no. & 15 & 20 & 35 \\
\hline
\end{tabular}

TABLE VII

LAMBETH WOMEN: IMPAIRMENT AND HOUSEHOLD SITUATION IN A SPECIAL SCALE GROUP

\begin{tabular}{|c|c|c|c|}
\hline \multirow[b]{2}{*}{ Impairment } & \multicolumn{2}{|c|}{ Household } & \multirow[b]{2}{*}{$\begin{array}{l}\text { Total } \\
\text { No. }\end{array}$} \\
\hline & $\begin{array}{l}\text { Married or } \\
\text { Living with } \\
\text { 3+ Others }\end{array}$ & $\begin{array}{c}\text { Nonmarried } \\
\text { Living Alone, or } \\
\text { with One Other }\end{array}$ & \\
\hline $\begin{array}{l}\text { Upper limbs } \\
\text { or internal }\end{array}$ & 3 & 9 & 12 \\
\hline $\begin{array}{l}\text { Other (lower } \\
\text { limbs, sensory } \\
\text { mental, etc.) } \\
\text { with one other }\end{array}$ & 15 & 8 & 23 \\
\hline Total no. & 18 & 17 & 35 \\
\hline
\end{tabular}

household situation, and may be related to impairments of early onset and a significant excess of disability among separated and divorced women. But this could influence only part of the strong connexion between the household factor and the disability ordering.

\section{EXAMPLE 2}

Guttman Scaling of Postsurgical Disability These data were collected during a pilot trial of a study to compare alternative policies of hospital nursing care after surgery. The subjects were 31 female patients, aged between 24 and 77 years (mean 41 years). The operations were mainly gynaecological and comprised six bilateral tubal ligations, 19 hysterectomies, three pelvic floor repairs, two cholecystectomies, and one appendicectomy. Patients who suffered early postoperative complications were excluded from the study and the sample, therefore, is of women having relatively straightforward recoveries after abdominal surgery.

The women were visited at home on approximately the third (Occasion 1) and twenty-first day (Occasion 2) after discharge. For each of a list of
16 activities, the subject recorded whether she was? currently performing the activity as usual, slower? than usual, not at all, or if the activity was not an usual one for her. Six items were rated as not being a usual one on both occasions by some women: theseo were-mowing the lawn, carrying fuel, running, polishing a floor, walking uphill or upstairs, andô carrying groceries. Since it would be impossible to scale such answers along an underlying dimension? of disability, the items were excluded from further consideration.

For the remaining 10 items, a division point was N established, so that patients could be described as being able or disabled on each item. The $\mathcal{O}$ division points for seven items were chosen so that $\mathrm{W}$ reasonable distributions of able and disabled subjects 0 resulted from Occasion 1, and for the remainder, 0 the division point producing the optimal Guttman $\Phi$ scaling was used. For nine items subjects were ${ }^{?}$ categorized as disabled if they could not do the activity as usual and for the remaining item, 'light work around the house', they were considered $\stackrel{\mathbb{Q}}{\odot}$ disabled only if they could not perform the activity@ at all. 


\section{RESULTS}

The Guttman ordering obtained is shown in Table VIII. The coefficient of reproducibility for Occasion $I$ is 0.90 and the coefficient of scalability is 0.58 , both criteria being approximately at the standards suggested earlier. This suggests that it is appropriate to apply the Guttman model to these data and to use it as a basis for scaling this kind of disability. Since only a small number of subjects were involved, it is impossible to perform a useful examination of nonscale types. However, this Guttman scale was established a posteriori, without any prior predictions of the ordering of items, so capitalizing on chance. To establish whether the ordering has any stability, the optimal ordering on Occasion 2 obtained from the marginal frequencies was correlated with the ordering on Occasion 1. A Spearman rank order correlation gives $r_{s}=0.93$, showing a very similar order for both occasions.

To test the validity of the ordering obtained on Occasion 1 it was imposed on the data of Occasion 2. Table VIII shows the item reproducibilities; the overall coefficient of reproducibility is 0.91 and the coefficient of scalability is 0.57 . Again these figures are within or close to the suggested range but this time without any capitalization on chance. This repetition does not give a completely independent test of the scaling in that the same subjects were involved on both occasions. However, subjects were scoring at very different levels on the scale on the two occasions.

\section{TABLE VIII}

POSTSURGICAL DISABILITY IN WOMEN

\begin{tabular}{|c|c|c|c|c|}
\hline \multirow{2}{*}{$\begin{array}{l}\text { Grade = } \\
\text { No. Items } \\
\text { Disabled }\end{array}$} & \multirow{2}{*}{\multicolumn{2}{|c|}{$\begin{array}{c}\text { Item Activity } \\
\text { Recovered at Each Grade }\end{array}$}} & \multicolumn{2}{|c|}{ Item Reproducibilities } \\
\hline & & & $\begin{array}{c}\text { Occasion } \\
1\end{array}$ & $\underset{2}{\text { Occasion }}$ \\
\hline 9 & \multicolumn{2}{|c|}{ Walk to table for meals .. } & 0.87 & 0.97 \\
\hline 8 & Dress self & . & 0.84 & 0.97 \\
\hline 7 & \multicolumn{2}{|c|}{ Light work around house } & 0.75 & 0.93 \\
\hline 6 & \multicolumn{2}{|c|}{ Walk around indoors } & 0.87 & $1 \cdot 00$ \\
\hline 5 & \multicolumn{2}{|c|}{ outside house } & 0.87 & $0 \cdot 77$ \\
\hline 4 & Wash dishes & . & 0.93 & 0.93 \\
\hline 3 & Cook meal & . & 0.97 & 0.87 \\
\hline 2 & \multirow{2}{*}{\multicolumn{2}{|c|}{$\begin{array}{l}\text { Use vacuum cleaner } \\
\text { Move light pieces of } \\
\text { furniture }\end{array}$}} & $1 \cdot 00$ & 0.93 \\
\hline 1 & & & 0.93 & 0.90 \\
\hline \multirow[t]{2}{*}{0} & Wash clothes & .. & 0.93 & 0.80 \\
\hline & \multicolumn{2}{|c|}{$\begin{array}{l}\text { Coefficient of reproducibility } \\
\text { Coefficient of scalability }\end{array}$} & $\begin{array}{l}0.90 \\
0.58\end{array}$ & $\begin{array}{l}0.91 \\
0.57\end{array}$ \\
\hline
\end{tabular}

The median scale score of items disabled on the first occasion was eight and on the second occasion only three.

An advantage in replicating the questionnaire with the same subjects is that the extent to which the cumulative undimensional model applies to individual subjects can be examined. For each subject, given the scores on Occasion 1 and Occasion 2 it can be predicted which items should have changed value, based on the scaling of Occasion 1. Taking the pattern of responses for each subject on the first occasion, it is expected that the subject will become able to perform more items in the order of the scale. In this way, over the 31 subjects, a total of 130 change predictions can be made of which 117 are fulfilled by the data. Using a randomization technique one finds that a result as good as or better than this would be obtained by chance on 1 in 1015 occasions. Clearly the model described the individual patterns very well.

\section{Discussion}

The disability scales in Tables I, II, and VIII may be validly used for similar populations and will be found easy to score. Validation of Guttman scales in other populations or with other items is also reasonably simple given the appropriate computing routines (Nie, Bent, and Hull, 1970), and is likely to be successful not only in disability but in any area characterized by cumulative growth or decay. Depending on the inferences looked for a scale may be read in three ways; as an order of disadvantage, as an order of deterioration, or as an order of recovery. The method appears suitable for use in a number of contexts.

Comparison of Disadvantages A Guttman scale grade makes it possible to order objectively the overall disadvantages of claimants to benefits who fall into scale types, provided that, for the population to which they are applied, each disability item on the scale is a disadvantage, and the items are representative of each person's activity. It is important to emphasize that any sample of items will fail to represent the activities of at least some individuals, and recognition of these cases needs the specific intuitive judgement of the assessor. Furthermore, nonscale cases will probably require some intuitive judgement. Guttman scaling provides the advantage that nonscale cases are easily recognizable, and the assessor has only to judge whether the normal procedure of assigning them to scale grades with the same number of 
disabilities is suitable in each case. The assessor's task is thus organized more simply and he is able to concentrate on the two specific questions where his judgement is appropriate.

Prediction OF Order OF Deterioration The community scales could be used in groups similar to the Lambeth population to anticipate and forestall the next stage of deterioration in activity. The scales for special groups indicate that prediction is likely to be improved by interpreting disability as a social choice rather than a mechanical necessity. The choice is progressive. As impairment increases the sick person reviews the field of item activities which could be modified and accepts one item for modification in accordance with customary rules. Sometimes choice will be restricted by the location of the impairment but the key to the interpretation would appear to lie in a deeper sociological understanding of sex roles, of the the division of labour in the household, and of wider family organization. In this respect, the discovery of Guttman scale structures in disability is of importance for the sociology of the family, for the scale structures provide a relatively objective test of hypotheses about customary values in this area.

Prediction OF Order OF Recovery The ordering obtained for surgical patients could be used wherever it would be useful to predict progress for patients similar to those involved in the postoperative study. For example, at a very simple level, the scale could be used clinically to give some guidance to such patients on what activities they should expect to perform at discharge and the order in which they will probably return to normal activities. Similar use of the community scales could be made to plan the rehabilitation of patients who are disabled in the longer term, and what has been said about the prediction of their deterioration applies equally to their rehabilitation. Furthermore this technique provides a measurement of outcome in terms of functional ability in the conduct of controlled trials of treatment and treatment policies.

We should like to thank Mrs P. Hawks, Mrs D. Vass, and Miss C. Lewis. This work was supported by the Department of Heaith and Social Security as part of the Community Hospital Research Programme.

Requests for reprints: Dr R. G. A. Williams, Health Services Evaluation Group, Department of the Regius Professor of Medicine, University of Oxford, 9 Keble Road, Oxford.

\section{REFERENCES}

Bennetr, A. E., Garrad, J., and Halil, T. (1970). Chronic disease and disability in the community: a prevalence study. Brit. med. J., 3, 762.

CARroll, D. (1962). The disability in hemiplegia caused by cerobrovascular disease. J. chron. Dis., 15, 179.

EkWALl, B. (1966). Method for evaluating indications for rehabilitation in chronic hemiplegia. Acta med.. scand., Suppl. 450.

GARRAD, J. and BennetT, A. E. (1971). A validated interview schedule for use in population surveys of chronic disease and disability. Brit. J. prev. soc. Med., 25,97.

GutTMan, L. (1950). The basis of scalogram analysis. In Measurement and Prediction, edited by S. A. Stouffer. Princeton University Press, Princeton, New York.

HARRIs, A. I. (1971). Handicapped and Impaired in Great Britain, Appendix D. HMSO, London.

HARRIS, R. and LuCK, G. M. (1972). Care of the Elderly, Report No. 717. Institute of Operational Research, London.

KaTZ, S., Ford, A. B., Moskowitz, R. W., JACKSO\& B. A., and JAFFE, M. W. (1963). Studies of illness in the aged. J. Amer. med. Ass., 185, 914.

Menzel, H. (1953). A new coefficient for scalogram analysis. Publ. Opinion Quart., 17, 268.

Nie, N. H., Bent, D. H., and Hull, C. H. (1970). Statistical Package for the Social Sciences, p.196. McGraw-Hill, London.

Rosser, R. M. and WATts, V. C. (1972). The measurement of hospital output. Int. J. Epidem., 1, 361.

SAINSBURY, S. (1973). Measuring disability, ch.3. Occasional Papers in Social Administration, No. 54 of the Social Administration Research Trust. Bell, London.

Schoening, H. A., ANDeregG, L., Bergstrom, D., Fonda, M., Steinke, N., and UlRich, P. (1965). Numerical scoring of self-care status of patients. Arch. phys. Med. 46,689.

Shanas, E., Townsend, P., Wedderburn, D., Henning,

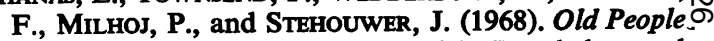
in Three Industrial Societies, p.26. Routledge and N Kegan Paul, London.

Torgrrson, W. S. (1958). Theory and Methods of Scaling, ch. 12. Wiley, New York.

Wood, P. H. N. (1974). Draft proposals for the ICD Unit of the World Health Organisation for a Classi-: fication of Handicaps (H Code).

WYLIE, C. M. and White, B. K. (1964). A measure of disability. Arch. environm. Hlth, 8, 834. 